\title{
Trabajos en yeso de Cosme Velázquez y su círculo para el Oratorio de la Santa Cueva
}

Santa Cueva (vista general) Interior de la Capilla Eucarística.

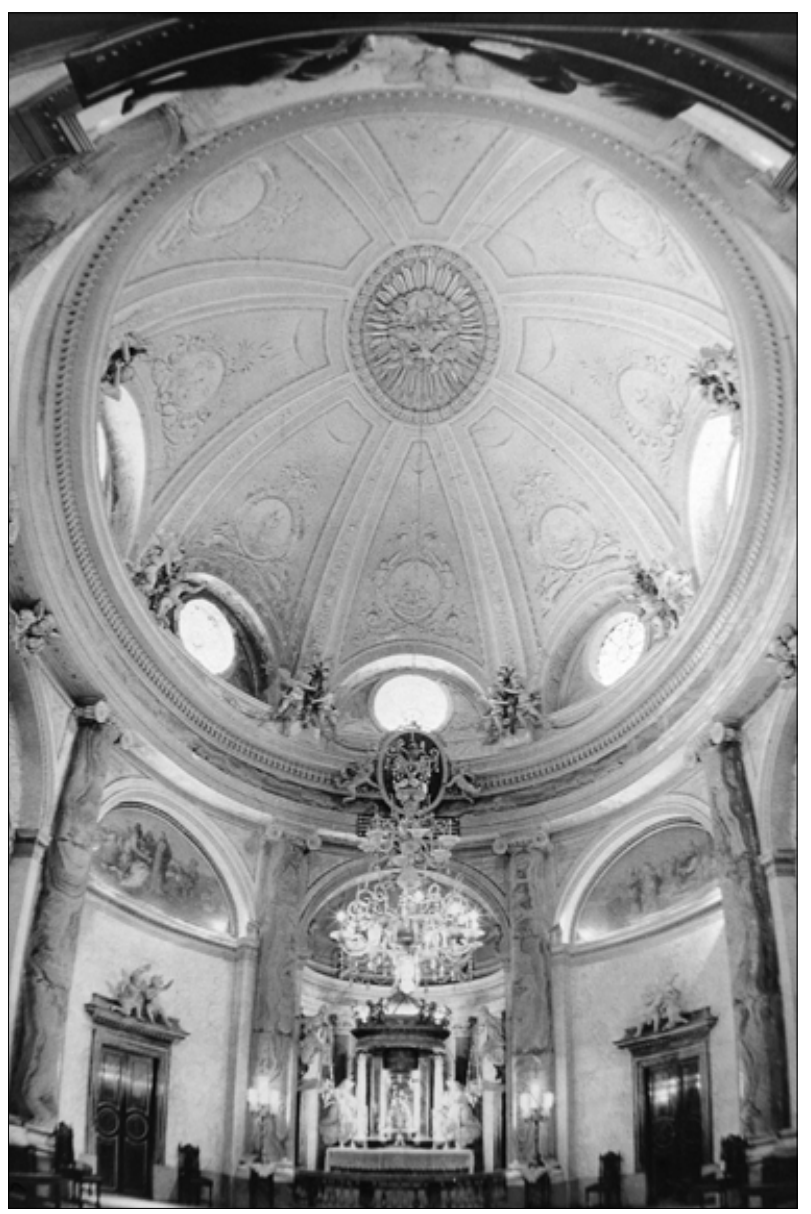

Juan y Lorenzo Alonso de la Sierra Fernández

Historiadores del Arte

\section{Introducción histórica}

La Santa Cueva resume a la perfección el ambiente cosmopolita de la sociedad gaditana a finales del siglo $X V I I I$, ya que en ella intervinieron creadores de diversa procedencia, tanto activos en la ciudad como foráneos. Al grupo local pertenecen los arquitectos Torcuato Cayón, su discípulo Torcuato Benjumeda, el pintor Franz Xavier Riedmayer y los escultores Jácome Baccaro, José Gandulfo o Cosme Velázquez. Entre los foráneos se encuentran el escultor granadino Manuel González y los pintores de la Corte, Francisco de Go- ya, José Camarón y Zacarías González Velázquez. A esta conjunción de diferentes manifestaciones artísticas se suma la música, representada por Joseph Haydn que escribió el oratorio de las Siete Palabras para acompañar el sermón en la mañana del Viernes Santo.

Encontramos los antecedentes de esa sociedad en la actividad comercial desarrollada tras el descubrimiento de América, especialmente incrementada con el traslado de la Casa de Contratación y Consulado de Indias en 1717. Al constituir Cádiz un núcleo urbano con escaso asentamiento de grandes familias nobiliarias, será la burguesía de negocios, integrada por individuos de origen diverso, quien protagonice la mayoría de las empresas artísticas desarrolladas a lo largo de la Edad Moderna '. Gracias a sus iniciativas se levantaron durante los siglos XVII y XVIII diversos templos y capillas, entre los cuales la Santa Cueva es quizá el último eslabón de la cadena, que cierra brillantemente una etapa de intensa actividad constructiva en la ciudad ${ }^{2}$. 
Coincide la realización de este oratorio con un período crítico para las manifestaciones artísticas en la Baja Andalucía. Dos siglos de dominio del Barroco dificultaron la expansión de la estética clasicista propiciada por las ideas de la llustración. Fue precisamente Cádiz uno de los pocos lugares donde, no sin dificultades, arraigaron las nuevas corrientes acogidas por los círculos cultos de la burguesía, que contaba con personalidades amantes de las Bellas Artes, cuyas ricas colecciones y bibliotecas se actualizaban continuamente. El anticuario Pedro de O'Cruley, el Conde de Maule - Sebastián Martínez son claro ejemplo de ello. Martínez mantuvo una amistad personal con Francisco de Goya que fue el vehículo de su presencia en $\mathrm{Cádiz}^{3}$. Representante del inquieto espíritu ilustrado es Gaspar Molina, marqués de Ureña, autor de las Reflexiones sobre la arquitectura, ornato y música del templo..., incansable viajero que influyó con sus diseños y opiniones en la difusión de los nuevos cánones estéticos ${ }^{4}$. También la iglesia diocesana contó con dos obispos, Juan Bautista Servera y José Escalzo y Miguel, afines al jansenismo y fieles a la política reformista impulsada por la corona ${ }^{5}$. La creación de la Escuela de Nobles Artes en 1789 sirvió para afianzar definitivamente estas ideas, a la vez que dio origen al nacimiento de una auténtica escuela artística local6.

Hacia 1730 había surgido en Cádiz una fraternidad religiosa dedicada a la práctica de los ejercicios conmemorativos de la Pasión de Cristo en las noches de los jueves, siguiendo los principios de la venerable madre sor María de la Antigua. La Congregación del Retiro Espiritual se reunía inicialmente en un local de la calle Garaicoechea, zona de prostíbulos, lo que despertó los recelos de algunos vecinos e hizo intervenir al obispo fray Tomás del Valle, que acudió disfrazado a una sesión y pudo comprobar el carácter piadoso de la actividad allí desarrollada. No obstante, para evitar malentendidos, propuso su traslado a algún templo de la ciudad, entre los que se eligió finalmente la ayuda de parroquia de Nuestra Señora del Rosario. La necesidad de disponer de un recinto retirado de las actividades parroquiales para desarrollar las prácticas penitenciales que incluían la flagelación de los penitentes, se vio satisfecha cuando en 1756 apareció un subterráneo que fue habilitado como capilla. Pocos años después, hacia 177| se inicia una relación fundamental para el futuro de la Santa Cueva, cuando el padre José Saénz de Santa María, Marqués de Valde-Iñigo, se hace cargo de la dirección espiritual de la congregación. Valde-íñigo, nacido en Vera Cruz (Méjico), pertenecía a una adinerada familia de comerciantes de origen riojano. Alcanzó gran fama como confesor y durante toda su vida se mantuvo fiel a las directrices de la Compañía de Jesús, pese a la supresión de la orden en 17677.

En principio puede parecer contradictoria la afinidad jesuítica del marqués de Valde-Íñigo con el ambiente ilustrado que animó los aspectos estéticos de la Santa Cueva, cuyo marcado carácter contrarreformista ha sido señalado por Santiago Sebastián ${ }^{8}$. Las intenciones de Valde-Î̃igo se enmarcan en los principios más puros de la Iglesia tridentina y su tendencia a entender el catolicismo de un modo íntimo y renovado no responde tanto al influjo jansenista, tan intenso en la España ilustrada, como al deseo de un sector del clero español de adaptar los principios originales de la contrarreforma a los nuevos tiempos ${ }^{9}$. Este mecenas encontró en los propósitos de la Congregación gaditana un medio ideal para canalizar sus inquietudes religiosas, pues sus prácticas devocionales coinciden con las de otras asociaciones promovidas por la Compañía de Jesús, como vemos en la capilla de la Buena Muerte del Colegio Imperial de Madrid ${ }^{10}$.

\section{Origen de la obra}

En I78I Valde-Iñigo encargó a los arquitectos Torcuato Cayón de la Vega y a su discípulo Torcuato José Benjumeda la construcción del oratorio subterráneo, tarea conjugada con la ampliación de la iglesia del Rosario, una de cuyas nuevas naves laterales debía apoyarse sobre la bóveda del oratorio. Esta capilla fue inaugurada el Jueves Santo 17 de abril de 1783 y quedó definida como edificio de planta basilical con tres naves y desprovisto de cualquier elemento ornamental superfluo. Para presidir el conjunto se eligió un patético calvario de madera policromada frente al cual se situaba la tribuna del director de los ejercicios ${ }^{\prime \prime}$.

Transcurridos diez años el marqués se vio heredero de toda la fortuna familiar, que decidió invertir en la mejora y ampliación del conjunto formado por la parroquia del Rosario y Oratorio de la Santa Cueva. En 1793 dio comienzo la construcción del oratorio eucarístico o capilla alta, cuyo diseño corrió a cargo de Torcuato Benjumeda. Se aprovechó esta ocasión para dar una entrada independiente al oratorio, ya que hasta entonces se accedía por la iglesia parroquial, y se varió la orientación de la capilla baja. En contraste con

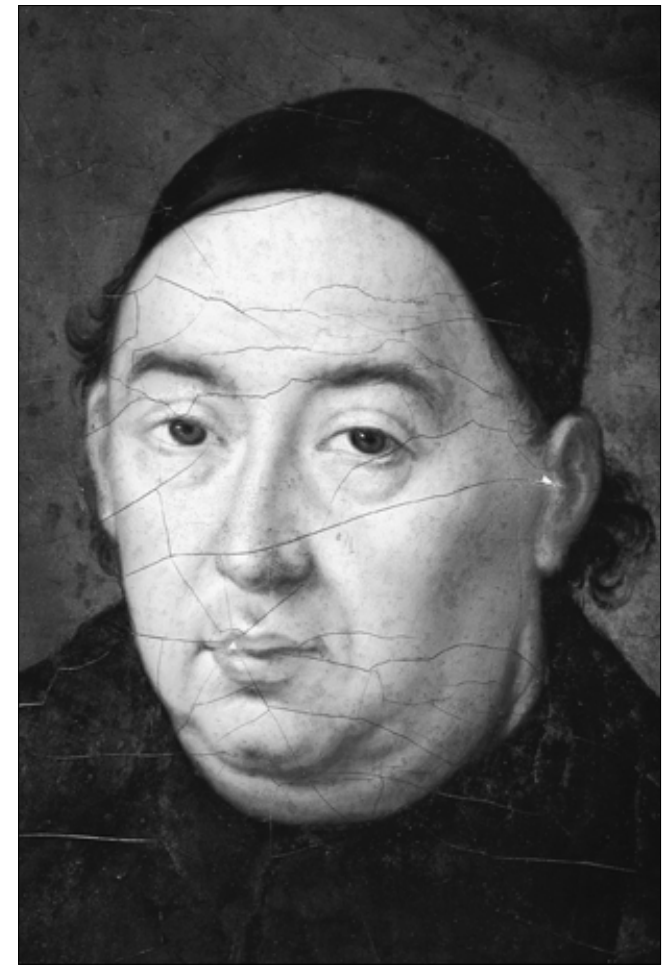

Retrato del Marqués de Valde-Íñigo. Pintura de Xavier Riedmayer 

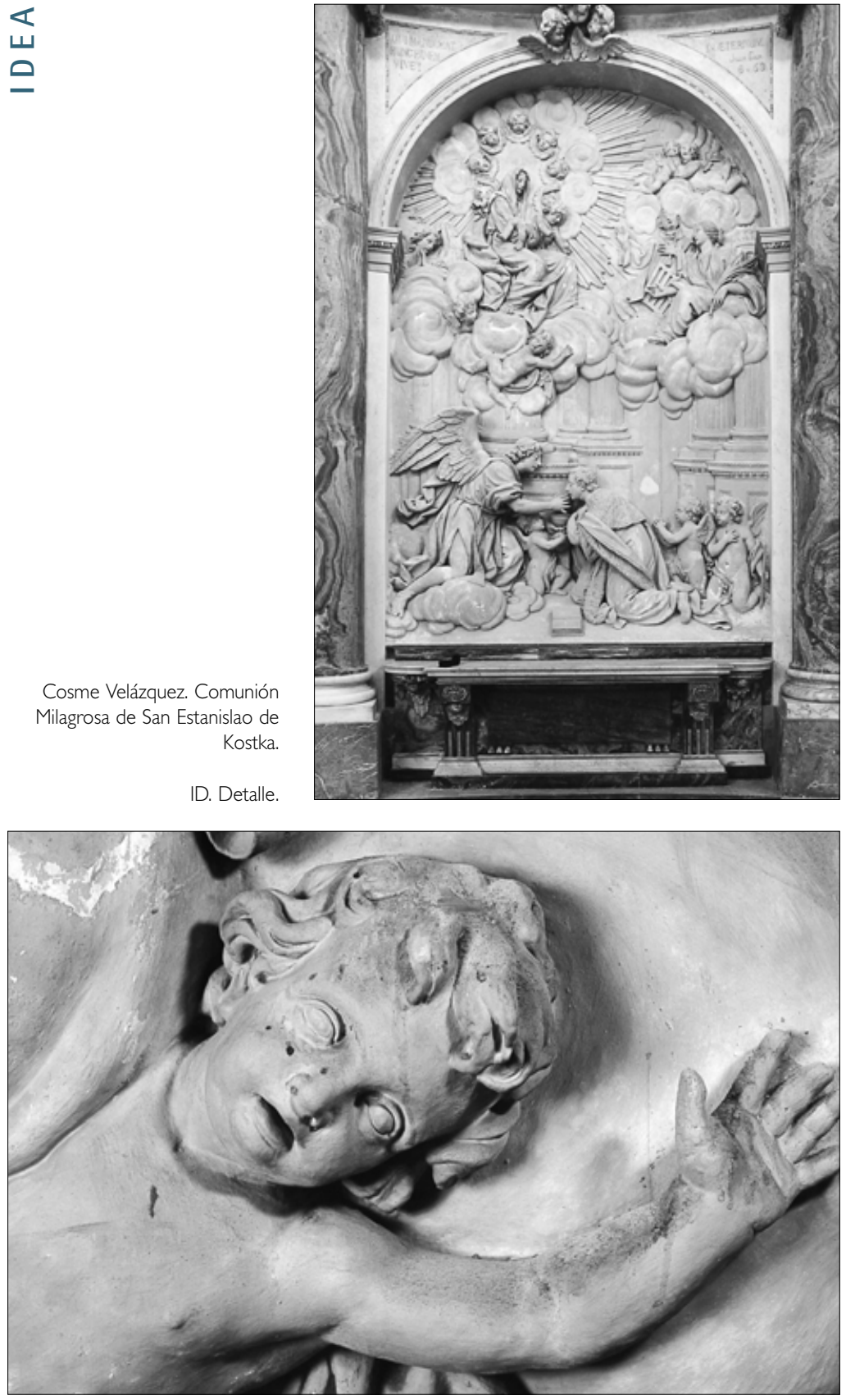

la austeridad del recinto penitencial se quiso dotar a la nueva construcción de la mayor suntuosidad. La propia biografía de Valde-Íñigo nos informa sobre su intención, pues allí se relata cómo durante un viaje a la Corte visitó el Palacio de Oriente y se entristeció al pensar que la Eucaristía no contaba con un edificio tan lujoso.

Bajo estas premisas Torcuato Benjumeda concibió un espacio de planta oval siguiendo la tradición manierista que se adecua perfectamente a la búsqueda de un espacio unitario, favorito de la Contrarreforma. Existe un antecedente en la propia ciudad de Cádiz para este modelo, el Oratorio de San Felipe Neri, diseñado a finales del siglo XVII según esquemas derivados de la iglesia romana de San Giacomo in Augusta 12. La capilla eucarística de la Santa Cueva recoge la tradición vignolesca y aportaciones barrocas de Bernini y Borromini, a través de creaciones hispanas cuyos ejemplos más cercanos encontramos en la obra de Ventura Rodríguez, yerno de Torcuato Cayón ${ }^{13}$.

Para desarrollar el repertorio iconográfico se acudió a una serie de pintores y escultores, entre ellos Francisco de Goya, autor de tres medios puntos ${ }^{14}$. El resultado es un perfecto ejemplo de integración de las artes que conecta con la genuina tradición del Barroco católico de inspiración berninesca. A las creaciones plásticas se une, además, la música, pues se encargó al compositor austriaco Joseph Haydn, entonces muy admirado en la Corte, la partitura de Las Siete Últimas Palabras de Cristo en la Cruz, que se interpreta en las mañana del Viernes Santo ${ }^{15}$.

En el repertorio escultórico Valde-línigo se mantuvo entre la tradición y la renovación. Para la capilla baja y vestíbulos acudió a artistas como los escultores genoveses afincados en Cádiz, José Gandulfo y Jácome Baccaro o foráneos como Manuel González, "El Granadino", que realizaron obras policromadas en madera tallada y barro cocido, afines aún al gusto barroco. Por su parte, toda la escultura de la capilla sacramental y los ángeles lampareros de la inferior están realizadas en yeso, solución que pretende evocar la escultura clásica según el gusto ilustrado ${ }^{16}$. En este grupo de esculturas y relieves, realizadas probablemente entre 1793 y 1796 y atribuidas tradicionalmente a Cosme Velázquez, se centra nuestro análisis.

\section{Iconografía}

Las esculturas objeto de la restauración acometida por el Instituto Andaluz de Patrimonio Histórico están compuestas por un florón con el Espíritu Santo, varios grupos de ángeles y los altorrelieves de San Estanislao de Kostka y San Luis Gonzaga. El Espíritu Santo, que centra el florón de la bóveda en la capilla sacramental, aparece según la iconografía habitual en forma de Paloma sobre una ráfaga dorada y rodeada por una gloria de querubines. Entre las representaciones de ángeles podemos diferenciar distintos conjuntos. En el tramo inmediato al presbiterio de la capilla penitencial se ubican dos parejas de ángeles lampareros que, entrelazados y simulando el vuelo, sustentan sendas lámparas. La capilla sacramental acoge en el presbiterio cuatro ángeles turiferarios, también niños, que aparecen sentados sobre la cornisa. En la nave ocho parejas de pequeños ángeles situados en el arranque de la bóveda portan haces de palmas con espigas y racimos de uvas en clara alusión a la Eucaristía. También son infantiles los dos ángeles que simulan sustentar un lienzo con el retrato del marqués de Valde-Ínigo sobre el presbiterio y las cuatro parejas de ángeles situadas sobre los guardapolvos de los confesionarios y vanos de acceso a las dependencias. En este caso portan atributos de la Pasión, en su mayoría desaparecidos, acordes con el sentido penitencial de la confesión. Bajo el lienzo de la Santa Cena que remata el vano de acceso una pareja de ángeles mancebos recostados sustenta un ostensorio. 
Los altorrelieves de San Estanislao de Kostka y San Luis Gonzaga siguen fielmente algunos episodios de la vida de estos jóvenes jesuitas, siempre relacionados con su devoción a la Eucaristía 17. Ambos se articulan en dos registros, en el primero San Estanislao, arrodillado y vestido con un manto de viaje, recibe en el interior de un templo columnado la comunión de manos de un ángel mancebo acompañado de otros tres ángeles niños. La zona superior es un rompimiento de gloria que representa a la Virgen con el Niño en sus brazos acompañada de Santa Bárbara y San Lorenzo. Una inscripción alusiva a la escena "VINIERON LOS ÁNGELES Y LE SERVÍAN", tomada del evangelio de San Mateo, capítulo IV, versículo I I, figura en la mesa de altar.

Se recoge en este relieve un episodio crucial para la vida del santo, cuando partió desde Viena hacia Augsburgo en busca del provincial de los jesuitas, Pedro Canisio, con el fin de ingresar en la compañía de Jesús, como le había solicitado la Virgen. Uno de sus biógrafos, Pedro Ribadeneira, describe así el acontecimiento aquí representado: "...y llegando a un pueblo, entró una mañana en una iglesia, que al parecer era de Católicos, con gran deseo y propósito de recibir el Santísimo Sacramento en ella; pero después supo, que la iglesia no era Católica, sino de herejes, y quedó sobremanera afligido y desconsolado. Volviose a Nuestro Señor y suplicole con afectuosas lágrimas que no le privase del mantenimiento de su alma que tanto deseaba. Oyole el Señor, y como Padre piadoso quiso regalar a su devoto hijo y enviole del cielo un Ángel de admirable hermosura, que con su mano le dio la Sagrada Comunión..." 18.

Otras referencias claves a la vida del santo quedan englobadas en la gloria. Santa Bárbara aparece porque era la patrona del colegio de la Compañía de Jesús de Viena, donde él estudió, y a ella suplicó no morir sin comulgar, pues se decía que sus devotos nunca fallecían sin los últimos sacramentos. Esta santa, perseguida por su padre como ocurrió también a San Estanislao, protagonizó otro episodio de crucial importancia para el santo, pues cuando éste se hallaba muy enfermo acudió a su habitación acompañada de unos ángeles que le administraron la comunión 19. La presencia de San Lorenzo obedece a que en la víspera de su fiesta del año 1568, Estanislao comenzó a pensar en su martirio y por su mediación escribió una carta a la Virgen suplicándole estar en el Cielo para la fiesta de la Asunción, deseo que le fue concedido, pues murió la madrugada de dicho día. La Virgen y el Niño que se vuelve en el regazo de su madre, tendiendo los brazos hacia el santo evoca el momento en que María le indicó que ingresara en la compañía de Jesús, dejándole al Niño sobre la cama. Por este motivo la iconografía más frecuente de San Estanislao lo presenta con el Niño Jesús en sus brazos.

En el relieve de San Luis Gonzaga la zona inferior escenifica el interior de una iglesia, ante cuyo altar San Carlos Borromeo asistido por varios jóvenes monaguillos procede a dar la primera comunión al santo en presencia de sus padres y hermano, mientras un ángel desciende a coronarle de flores. El rompimien- to de gloria está centrado por la Virgen sobre una ráfaga con orla de querubines y acompañada de ángeles niños, ante la cual se arrodilla San Luis vestido con hábito de novicio jesuita. La inscripción de la mesa es en este caso "POR VUESTRA SALUD OS RUEGO QUE COMÁIS" tomada de los Hechos de los Apóstoles, capítulo XXVII, versículo 34.

El relato es recogido por Ribadeneira en los siguiente términos: "... vino a Castellón el Bienaventurado Cardenal Borromeo, Cardenal de la Santa Iglesia, y arzobispo de Milán, a quien Dios dio en estos tiempos a su Santa Iglesia y dechado de Prelados, y tuvo con nuestro Luis largas pláticas y quedó admirado de los dones de Dios, y conoció en aquel pecho de un mozo de tan pocos años tanto espíritu y fervor, como si fuera ya varón perfecto. Exhortolo el Cardenal a comulgar y hacerlo a menudo (porque hasta entonces no había recibido al Señor) y le dio una breve instrucción de cómo se había de aparejar para recibirle. Y el santo mozo, la primera vez que hubo de comulgar, hizo extraordinaria diligencia, examinando toda su vida pasada muy menudamente y se confesó con tan grande humildad, dolor y lágrimas, que el Confesor tuvo harto que aprender de él; y algunos días antes de comulgarse, todos sus pensamientos, razonamientos y cuidados, eran de este Santísimo Sacramento, y este era el blanco de su meditaciones y oraciones..." 20.

En el rompimiento se representa a la Virgen en su Asunción recibiendo a San Luis en la Gloria, ya que cuando el santo contaba 16 años y se encontraba un 15 de agosto en la iglesia del Colegio Imperial de Madrid oyó su voz que le decía "Entra en la Compañía de Jesús" 21.

Todas estas obras se incluyen en un amplio programa iconológico con el que alcanzan su auténtico significado ${ }^{22}$. La distancia cronológica entre la realización de las dos capillas no fue obstáculo para que se lograse un resultado unitario, en cuya concepción sería definitiva la personalidad de Valde-Íñigo, quien enriqueció entonces el ya existente del oratorio primitivo y amplió su contenido con la inclusión de la capilla sacramental. El mensaje final anima al pecador a practicar la penitencia como medio de purificación para llegar a la recompensa eucarística. En la sobria fachada, casi de tipo civil, se encuentra un lienzo callejero dedicado a la Virgen del Refugio que sirve de invitación a los viandantes. En él la Virgen acoge bajo su manto sin distinción alguna a los miembros de los tres estados, como muestra del carácter abierto de la congregación, aunque siempre limitada exclusivamente a los hombres.

En el vestíbulo una imagen de la Virgen dolorosa sedente invita a entrar, como indica la inscripción que la acompaña: "Andad hijos míos porque yo he sido dejada sola". Desde aquí se abren dos escaleras laterales para acceder al oratorio bajo, si descendemos por la derecha encontramos una imagen de Jesús Nazareno en una de sus tres caídas que de algún modo sirve al penitente para proyectar su propia caída en el pecado. Antes de entrar en el oratorio una inscripción nos recuerda los objetivos propuestos: "Todo el que 
desee alcanzar el Reino eterno del Cielo, venga sediento a este lugar, pues aquí está preparado el camino". Ya en el interior sólo se vislumbra al fondo un patético calvario de tamaño natural en el que Cristo agonizante es acompañado por la Dolorosa, San Juan y las tres Marías. En el tramo anterior al presbiterio dos parejas de ángeles de yeso sustentan las lámparas que alumbran el altar.

Blanco White, que fue invitado por Valde-Íñigo a una de las ceremonias de la Cueva, describe el ritual que allí se realizaba tres días a la semana al caer la tarde: "Inmediatamente después de mi sermón dos sacerdotes portando sendos manojos de disciplinas hechas de cuerda y dotadas de gruesos nudos, empezaron a recorrer la capilla en toda su longitud suministrando a los asistentes estos instrumentos de penitencia. Terminado el reparto se apagaron las escasas lámparas del lugar con la única excepción de una pequeña vela encerrada en una linterna sorda. Al hacerse la oscuridad uno de los sacerdotes entonó con voz quejumbrosa una corta narración de la Pasión de Cristo, en tanto que los devotos asistentes se apresuraban a despojarse de la ropa que les cubría el lugar del cuerpo que iban a castigar... Concluido el relato de la Pasión se entonó el Miserere, que bien pronto tuvo el acompañamiento del ruido de los azotes... Contra lo que pudiera suponerse, el ruido y la violencia de los azotes va en aumento conforme el salmo, cantado alternativamente por el sacerdote y la congregación, se acerca a su fin... La flagelación acabó al dar el sacerdote la consabida señal de unas palmadas, y tras una nueva pausa de cinco minutos para que los penitentes pudieran vestirse, se abrió la linterna y se volvieron a encender las lámparas" 23 .

En la mañana del Viernes Santo se celebraba aquí el sermón de las Siete Palabras, que según el testimonio del propio Haydn seguía este ritual: "A mediodía se cerraban las puertas y la orquesta empezaba a tocar. Después de la introducción el obispo subía al púlpito, pronunciaba una de las Siete Palabras y la acompañaba de algunas reflexiones. Bajaba enseguida, se arrodillaba ante el altar y así permanecía unos momentos. Esa pausa la llenaba la música. El obispo subía y bajaba seis veces más, y cada vez, tras su homilía, tocaba la orquesta..."24.

Al salir del oratorio para ascender por el tramo izquierdo de la escalera, el fiel encontraba una imagen policromada de Cristo atado a la columna, que recuerda el carácter redentor de la penitencia practicada. El tono ascético que domina en el ámbito inferior cambia cuando se inicia la subida a la capilla eucarística, cambio anunciado por un espacio arquitectónico más ornamentado y lujoso. Originalmente presidía el rellano de la escalera un lienzo de la Santa Cena, reemplazado en el siglo XIX por una vitrina con el Corazón de Jesús, devoción muy querida por los jesuitas y que Valde-Iñigo había dispuesto originalmente en el vestíbulo de oratorio eucarístico ${ }^{25}$. Allí una imagen del Buen Pastor invita a entrar con la siguiente inscripción: "Entra, bendito del Señor, ¿Por qué te has de quedar fuera?".

En la capilla, concebida como un gran sagrario, el lujo se despliega en todos los detalles y el programa está dedicado a exaltar la Eucaristía. Cinco lienzos sobre los vanos de los intercolumnios representan otros tantos motivos eucarísticos: El Rocío del Maná, El Convite Nupcial, Las Bodas de Caná, La Multiplicación de lo Panes y los Peces y La Última Cena. Preside el conjunto un tabernáculo en forma de templete adorado por dos ángeles mancebos, solución inspirada en la que empleó Bernini para la capilla sacramental de San Pedro de Roma ${ }^{26}$. Los ángeles y relieves de yeso inciden en la misma temática. Dos ángeles mancebos que portan un ostensorio complementan el lienzo en el que se representa la institución de la Eucaristía. En los confesionarios parejas de ángeles niños portan atributos de la Pasión, como alusión a la penitencia. Sobre la cornisa los portadores de motivos eucarísticos indican una gloria centrada por el Espíritu Santo, que ocupa la clave de la bóveda, y otros inciensan el sagrario alrededor del altar.

Los altorrelieves de San Estanislao de Kostka y San Luis Gonzaga son piezas claves en el programa de las capilla. Su clara vinculación jesuítica evidencia el origen de los principios que inspiraron al fundador ${ }^{27}$. Para la Compañía de Jesús, muchas veces acusada de estar excesivamente ligada a los asuntos terrenales, estos santos suponían el contrapunto espiritual y se referían a ellos como "ángeles revestidos de naturaleza humana" 28. Ambos eran el mejor ejemplo para los miembros de la Congregación de la recompensa que esperaba a su penitencia y, a su vez, suponen todo un compendio de alusiones a los más queridos principios de la Iglesia contrarreformista, el culto a la Virgen, presente en ambos relieves, y a los santos, valoración de la penitencia e importancia de la Eucaristía como vehículo de salvación.

Las aparentes contradicciones que pueden derivarse entre las prácticas de la congregación, siempre asociadas a cierto halo de misterio, la época y el ambiente social, han provocado algunas interpretaciones curiosas. Desde la óptica del siglo XX, tan alejada de la mentalidad del Antiguo Régimen y de la complejidad de un momento en el que conviven tradición y cambio, se ha querido ver en este Oratorio un recinto afín a las prácticas de algunas sociedades secretas, siempre animadas por la burguesía. Nada más lejos de la realidad, el análisis iconográfico e iconológico evidencian, que lejos de buscar nuevas fórmulas, la Santa Cueva entronca, como ya se comentó anteriormente, con los más estrictos principios de la Iglesia tridentina desde la óptica estética de la llustración.

\section{Los autores}

Tradicionalmente se atribuyen a Cosme Velázquez todos los trabajos escultóricos en yeso que guarda la Santa Cueva. Un testimonio contemporáneo a la culminación del Oratorio, el del conde de Maule, le identifica como autor de buena parte de las esculturas. En concreto hace referencia explícita a los relieves de los altares laterales y a la decoración escultórica del mayor. Por el contrario silencia la autoría de los ángeles lampareros de la capilla subterránea, florón y turifera- 
rios del presbiterio, así como los restantes del oratorio alto, distribuidos sobre la cornisa, confesionarios y vano de acceso ${ }^{29}$.

En efecto, la mayor parte de los yesos del oratorio evidencian su estilo con claridad si se comparan con otras obras suyas conservadas en la ciudad. No obstante, un análisis estilístico muestra ciertas divergencias entre algunos grupos que nos permiten plantear la participación de otros escultores. De hecho el marqués de Valde-Íñigo acudió en aquellas fechas a otro escultor, el maestro granadino Manuel González, para realizar las imágenes de la Virgen de la Soledad, Buen Pastor y Jesús Caído ubicadas en el mismo oratorio. A esta intervención de distintos escultores debe obedecer el significativo silencio del conde de Maule cuando hace referencia a los grupos de ángeles. En algunos se observan rasgos más puramente clasicistas que pueden relacionarse con la producción de José Fernández Guerrero. La ausencia de fuentes documentales que confirmen este planteamiento nos obliga a mantener esta cuestión en el terreno de la hipótesis 30.

Cosme Velázquez Merino (1755- I837), nacido en Logroño, se formó en la Academia de San Fernando de Madrid con los prestigiosos escultores Pierre y Robert Michel| ${ }^{31}$. En esta institución consiguió varios premios, dos de ellos con los relieves que representaban $L a$ rendición de Jaén y El Nacimiento del futuro Fernando VII, y otro en la clase de modelado de yeso, méritos que posiblemente influyeron para que Ventura Rodríguez le encargase unos ángeles destinados al retablo del madrileño Colegio de las Niñas de la Paz, hoy desaparecido. La vinculación familiar entre Ventura Rodríguez y el arquitecto gaditano Torcuato Cayón, su suegro, puede ser el origen del traslado de Cosme Velázquez a Cádiz, hasta donde llegó reclamado por el obispo José Escalzo para trabajar en las labores escultóricas de la nueva parroquia de San José que se construía en extramuros ${ }^{32}$. Dicho templo se levantaba bajo la dirección de Torcuato Benjumeda, tras la muerte de su maestro, Cayón, en 178333. A partir de entonces residió en Cádiz y tras crearse la Escuela de Nobles Artes en 1789 fue nombrado director de escultura, donde desarrolló una importante y dilatada labor docente a la vez que atendía numerosos encargos de tipo civil y religioso. La actividad de este artista constituye uno de los motores fundamentales en el triunfo de la renovación estética del Cádiz ilustrado.

Su prestigio profesional hizo que, además de ser director de escultura en la Escuela de Cádiz fuera nombrado académico de mérito de las academias Real de San Fernando de Madrid y San Carlos de Méjico, así como socio de mérito de la de Sanlúcar de Barrameda. También consiguió el título de Escultor de Cámara honorario, que le concedió Fernando VII en 1817. Precisamente entre los documentos presentados para la solicitud de este cargo se encuentra un memorial del autor que nos ilustra sobre parte de su curriculum: "... Don Cosme Velázquez fue elegido director de Escultura de dichos Estudios, y por el lltmo. Sr. Obispo de esta ciudad, por el Sr. Gobernador de Ella y por los Sres. Diputados del Ayuntamiento que forman este establecimiento en virtud de los Reales Despachos del Supremo Consejo de Castilla expedidos a consulta de S. Majestad dicho nombramiento se exhibe en este Profesor en consideración a su mérito y conocimiento artístico, los cuales han sido conocidos por la Real Academia de San Fernando, habiéndole creado su académico de mérito. Desde luego se le comisionó en el arreglo y composición de la colección de estatuas venidas de Roma para el uso de estos estudios. En ellos ha formado modelos de las cinco órdenes de Arquitectura, a fin de instruir mejor a los que se dedican al estudio de este arte. Por la necesidad de imponer a los alumnos adelantados en la copia del natural, en el conocimiento de los trajes y pliegues, se le encargó la construcción de un maniquí que ha concluido con la mayor prolijidad e inteligencia para el intento que se propuso la Junta. Presentó un vaciado en yeso de la Medalla que trabajó para su recepción en dicha Real

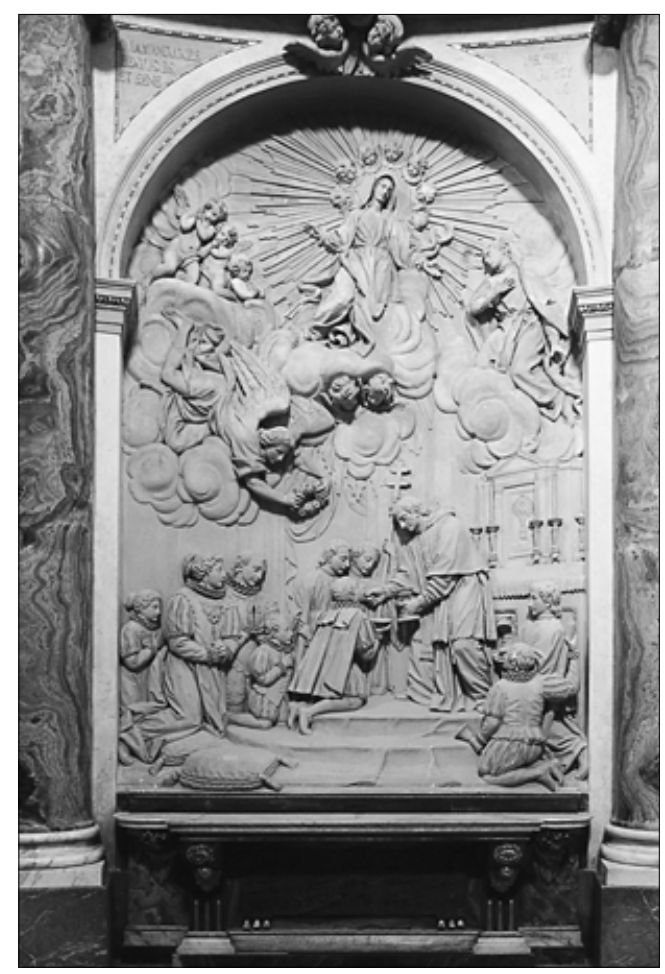

Cosme Velázquez. Primera Comunión de San Luis Gonzaga. ID. Detalle.

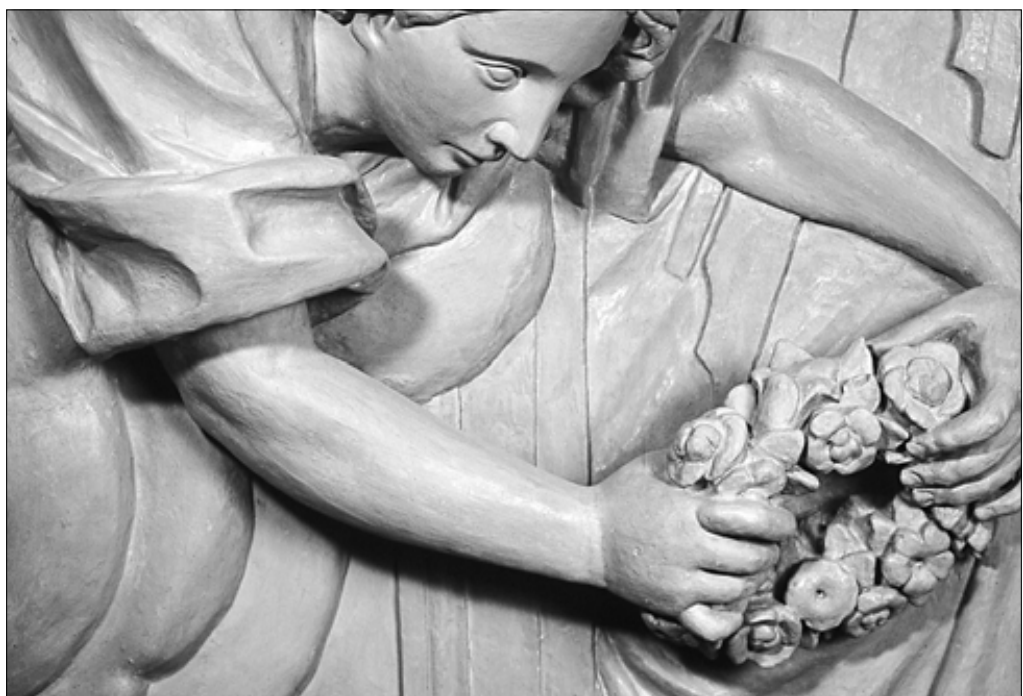


는

Cosme Velázquez. San José Parroquia de San José en extramuros. Cádiz.

Academia, el cual fue colocado en la sala terminada de juntas. En la misma se ha puesto una medalla en yeso que representa la triunfante entrada en Roma de Lucio Cornelio Balbo. Por encargo de un distinguido comerciante de esta ciudad trabajó en mármol la estatua pedestre del Sr. Rey don Carlos III, que se colocó en La Habana. Se ha ocupado en los adornos y decoración de las casas y edificios públicos en las ocasiones que por los motivos plausibles de la Monarquía, ha debido esta ciudad, manifestar su júbilo y satisfacción. De los méritos artísticos de este profesor deberán juzgar los inteligentes y las citadas Academias... "34.

El carácter del documento hace que se silencie la mayoría de su extensa producción de tipo religioso. Suyos son los ángeles y otras esculturas ubicadas en la mayoría de los retablos de la parroquia gaditana de Nuestra Señora del Rosario y la de San Juan Bautista de Chiclana ${ }^{35}$. También, como hemos dicho, se encargó de realizar el repertorio escultórico de la parroquia de San José, en el barrio del mismo nombre situado a extramuros de la ciudad, conjunto del que sólo se conserva la imagen del titular en mármol de la fachada principal. Para la Catedral Nueva realizó la escultura en mármol de uno de los Santos Patronos de Cádiz, cuyo paradero desconocemos y para la Colegiata de Jerez de la Frontera el aguamanil de la sacristía ${ }^{36}$. También es autor del crucificado que actualmente se conserva en el presbiterio de la parroquia de San Pedro y San Pablo en San Fernando ${ }^{37}$. Cuenta con otros trabajos de tema profano no citados en el documento anterior entre los que sobresalen el monumento funerario de Gravina creado para la iglesia gaditana del Carmen, que se encuentra actualmente en el Panteón de Marinos llustres de San Fernando y el busto en mármol de Alejandro Risso realizado para el Hospicio, hoy expuesto en el Museo de las Cortes de Cádiz ${ }^{38}$. Para la Escuela de Nobles Artes de Cádiz, además de los trabajos citados en el documento anterior, creó dos esculturas en yeso, Apolino y Fauno, diseñadas como modelo para los estudiantes. Asimismo realizó los grupos mitológicos y reproducciones numismáticas que decoran la fachada del Ayuntamiento gaditano y una alegoría de la Justicia en piedra para la Cárcel Real, hoy desaparecida ${ }^{39}$.

Tuvo a su cargo algunas decoraciones efímeras, como las realizadas con motivo de la visita de Carlos IV a Cádiz, para la que elaboró cinco estatuas que decoraban el muelle y cuatro bajorrelieves con los retratos de los infantes e infantas destinados a la plaza de San Antonio ${ }^{40}$. De este conjunto debe proceder la alegoría de La Fama que se colocó posteriormente en la clave de la cúpula de la Catedral Nueva y recientemente ha sido retirada durante unos trabajos de restauración que pretendían construir una linterna. Su versatilidad artística se extendió también al campo de la retablística, pues sabemos que en 1787 contrató con las hermandades del Santísimo Sacramento y Ánimas la realización de un retablo en madera para uno de los colaterales del crucero en la iglesia de San José, obra perdida en 1936 que posiblemente siguiera un diseño de Torcuato Benjumeda ${ }^{4}$.

El catálogo de sus obras, aún pendiente de un estudio exhaustivo, puede verse ampliado a diversos trabajos claramente relacionados con su producción, entre los que se incluirían los ángeles tenantes que decoran la fachada principal de San Juan Bautista en Chiclana de la Frontera. Con él se relaciona también la imagen de San Fermín que ocupa uno de los retablos colaterales de la parroquia gaditana del Rosario ${ }^{42}$. Se le ha atribuido erróneamente la desaparecida talla del Cristo de las Penas de San Lorenzo, aunque en realidad se trataba de un profeta realizado por Doménico Giscardi para el monumento de la Semana Santa de la Catedral que fue reformada a mediados de nuestro siglo por Miguel Laínez para adaptarla a su nueva finalidad ${ }^{43}$. Igualmente se le ha considerado autor del relieve marmóreo de la Conversión de San Pablo situado en la fachada de la capilla del mismo título, obra barroca realizada en Génova a finales del siglo XVII, cuyas características permiten relacionarlas con la producción de Esteban Frugone ${ }^{44}$.

En sus trabajos, que cubren casi todas las técnicas escultóricas, Cosme Velázquez se comporta como un creador de la llustración, pues mantiene elementos de tradición barroca inspirados en los grandes maestros franceses e italianos, conjugados con ciertos aires más clasicistas. Su conocimiento de la técnica del modelado y vaciado en yeso, aprendida en los círculos académicos de la Corte, y el prestigio alcanzado como titular de escultura en la Escuela local de Nobles Artes, le convirtieron en el candidato ideal para realizar el repertorio de la Santa Cueva.

José Fernández Guerrero (1748-|826), nacido en Ubrique, se formó en la Real Academia de San Fernando, fue profesor de la escuela de dibujo creada por los plateros de Cádiz en 1777 y más tarde en la fundada por el conde $O$ 'Reilly, para desempeñar con posterioridad el cargo de Teniente de Escultura en la Escuela de Nobles Artes de Cádiz ${ }^{45}$. En su breve catálogo se cuentan las esculturas en yeso de Balbo el Menor y Columela conservadas en el despacho de la alcaldía de Cádiz y cuatro relieves de temas alegóricos 
protagonizados por Hércules, que se guardan en la sala de juntas de Academia Gaditana de Bellas Artes. Otros relieves mitológicos actualmente desaparecidos representaban a Cádiz acogiendo a las Bellas Artes e Hipólito y Fedra. En bronce realizó diez esculturas para la localidad manchega de Almuradiel y en el campo de las creaciones efímeras, se sabe que fue autor del catafalco de la reina Isabel de Braganza levantado en la Catedral de Cádiz ${ }^{46}$. Creó algunas imágenes procesionales de candelero como la Divina Pastora de Capuchinos de Sevilla o las dolorosas de San Pablo de Cádiz y de la parroquia de Arahal, trabajo con el que colaboró en un retablo diseñado por Ceán Bermúdez ${ }^{47}$. Artista realmente polifacético, cubrió además de la escultura los campos de la orfebrería y el dorado, aunque de estas actividades sólo conservamos referencias documentales en las que consta que fue autor de un templete procesional de plata para la Virgen del Carmen y en 1782 presentó un presupuesto para dorar el retablo que preside dicha imagen en la iglesia del convento gaditano de los carmelitas ${ }^{48}$.

Su obra responde a modelos de clara inspiración clásica en los que no se aprecian las pervivencias de tradición barroca que veíamos en Cosme Velázquez. Utiliza un modelado más sobrio, con rasgos físicos y ademanes inspirados en la estatuaria grecorromana. Tales características habrían convertido a este autor en auténtico precursor de la renovación neoclásica de la escultura gaditana si la escuela hubiera contado con alumnos destacados de esta especialidad, hecho que lamentablemente no llegó a producirse. Las cuatro parejas de ángeles pasionarios situadas sobre los vanos y confesionarios de la capilla sacramental de la Santa Cueva se ajustan mejor a estos criterios que a los manejados por el escultor riojano, lo que nos permite plantear la hipótesis de su autoría. Ciertamente, durante aquellos años Fernández Guerrero era el único escultor local que podía afrontar una empresa de este tipo, pues, como hemos señalado, la escuela gaditana no contaba con otros escultores. Además, la relación laboral entre ambos artistas hace más verosímil esa colaboración, que consta en otras empresas. La complejidad del encargo y el escaso margen de tiempoapenas tres años- para su realización es otro argumento que apoya esta hipótesis.

\section{Análisis estilístico}

Cosme Velázquez fue el autor de las piezas más importantes del conjunto de yesos, es decir, los altorrelieves del oratorio eucarístico, que resuelven los altares laterales siguiendo un esquema muy del gusto académico. En ambos casos se emplea una solución compositiva muy similar que contempla la división en dos registros, uno terrenal y otro celestial, siguiendo prototipos originados en la escuela pictórica boloñesa de siglo XVII. Éstos fueron especialmente difundidos a través de la obra de los Carracci o Guido Reni y también se utilizaron por escultores de tendencia clasicista como Alessandro Algardi. Es evidente que Cosme Velázquez hubo de seguir algún modelo impreso sugerido por el propio Valde-Íñigo, pues la complejidad de su mensaje iconográfico, perfectamente ensamblado en la intencionalidad global del conjunto, tuvo que partir del promotor. Sólo él, con una sólida formación jesuítica tan poco acorde con los tiempos que corrían, pudo indicar la perfecta ubicación y resolución de estos relieves.

Es muy posible que se utilizara como fuente iconográfica la colección de estampas incluida en la obra de Biverus, Sacrum Oratorium, editada en Amberes en 1634. En ellas se reproducen las pinturas que decoraban la antigua iglesia del noviciado de los jesuitas en el Quirinal de Roma, sustituida posteriormente por la actual iglesia de San Andrés que diseñara Bernini. En cualquier caso las comuniones milagrosas de San Estanislao vuelven a aparecer en la decoración de la habitación del Santo, contigua a San Andrés, en la que tuvo un especial protagonismo el pintor jesuita Andrea Pozzo 49. La difusión de este motivo iconográfico es relativamente frecuente en los templos jesuíticos y encontramos algunos ejemplos en España e Iberoamérica ${ }^{50}$.

Cosme Velázquez plasma en estas obras los rasgos más significativos de su estilo, que alcanza aquí un sereno equilibrio entre la agitación barroca de algunos elementos y la concepción clasicista del conjunto. Muy cercanos a los altorrelieves son los dos ángeles mancebos que portan una custodia apoyados sobre el frontón que remata el vano de acceso. Su esquema

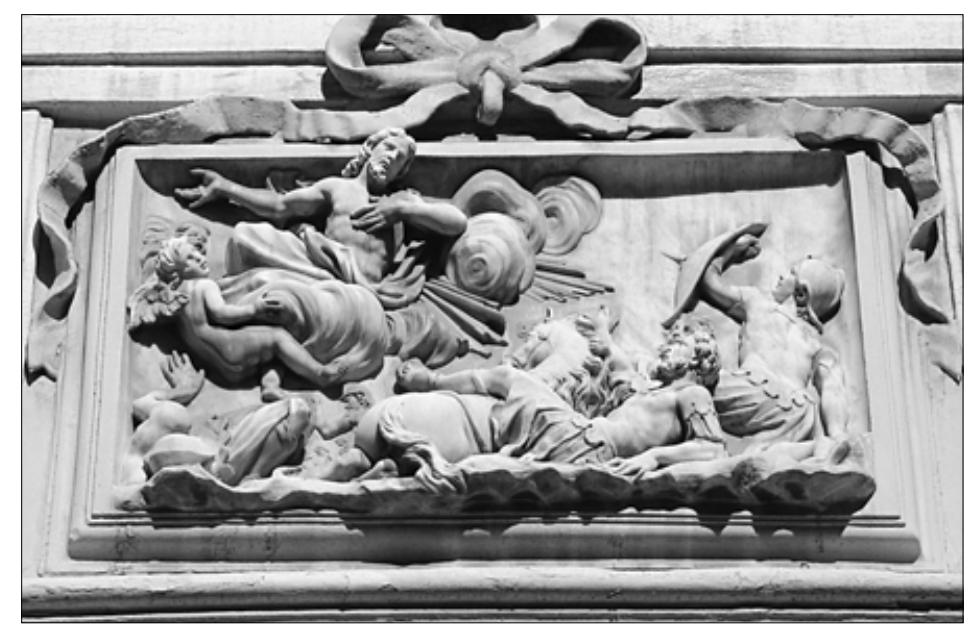

fue utilizado también por el autor en otras composiciones similares, como las que presentaban los retablos de San José y San Fermín en la contigua parroquia del Rosario. Más barrocos son los grupos de querubines ubicados en las claves de los arcos y florón de la bóveda en torno al Espíritu Santo, rasgo que también se aprecia en los ángeles que coronan las cornisas del presbiterio y cuerpo de la iglesia. Estas últimas creaciones y las parejas de ángeles lampareros de la capilla subterránea evidencian la inspiración berninesca tan querida por los más destacados creadores del academicismo español y son cercanos a los grupos mitológicos resueltos con figuras infantiles que decoran algunos vanos del Ayuntamiento de Cádiz, obra documentada de Cosme Velázquez.
Anónimo italiano de finales del $\mathrm{S}$. XVII. Conversión de San Pablo. Iglesia de San Pablo, Cádiz. 
Los ángeles pasionarios ubicados sobre los confesionarios y vanos de la capilla sacramental que relacionamos con Fernández Guerrero se distancian de la homogeneidad barroca de los grupos anteriores. Su concepción es más contenida y clásica, rasgos que se hacen más evidentes en la resolución de las cabezas, disposición de los cabellos y paños de pudor. Estas características coinciden con las de su obra más conocida, la estatua de Balbo el Menor conservada en el despacho de la alcaldía del Ayuntamiento gaditano.

Ajena a los anteriores grupos es la pareja de ángeles que sustenta el retrato del marqués de Valde-Ínigo sobre el arco de acceso al presbiterio. En esta ocasión es fácil apreciar su escasa calidad, ya que se aprecian desproporciones que podrían estar relacionadas con una posible reutilización de piezas más antiguas. No hay que olvidar que fueron realizados fuera del programa inicial, pues el cuadro se colocó tras fallecer Valde--Ínigo, entre 1804, fecha de su muerte y 18 |3, cuando se publica el tomo XII del Viaje de España... de Maule, donde ya se cita en esta ubicación ${ }^{51}$.

\section{Restauraciones y modificaciones}

Desde la época de su construcción se valoró el conjunto de la Santa Cueva como una de las manifestaciones culturales más significativas de la ciudad y así lo recoge la bibliografía posterior. Esta valoración debió motivar sucesivas intervenciones tanto de conservación como de mejora, que incorporaron nuevos elementos al planteamiento original ${ }^{52}$. Entre las que afectaron a la disposición inicial del Oratorio hemos podido documentar varias; la primera, ya comentada, es la realizada poco después de morir Valde-ínigo en I 804 cuando se colocó sobre la clave del arco de acceso al presbiterio un retrato suyo realizado por Riedmayer ${ }^{53}$. Años después, en 1846, con motivo del traslado al Oratorio de los restos del fundador se construyó un monumento funerario en el vestíbulo de la capilla alta donde hasta entonces se ubicaba la vitrina con el Corazón de Jesús, que hoy se encuentra en el rellano de la escalera. Para colocarla allí fue retirado un lienzo de la Instauración de la Eucaristía pintado por Juan Navarro ${ }^{54}$. La intervención más importante tuvo lugar pocos años antes de celebrarse el primer centenario del edificio, entre 1886 y $\mid 887$. Fue entonces cuando el pintor de origen italiano Antonio Cavallini decoró al fresco la bóveda de la capilla sacramental $y$, en consecuencia, es muy posible que todo el conjunto fuera sometido a un "remozado" general55.

\section{Conclusiones}

El conjunto de yesos del oratorio de la Santa Cueva de Cádiz constituye una importante muestra de la actividad artística desarrollada en la ciudad a finales del siglo XVIII. Durante ese período se fraguó una renovación estética liderada por la Escuela de Nobles Artes que, por su singularidad en el entorno andaluz, protagoniza la vanguardia creadora de la época en nuestra región. Precisamente es en este recinto religioso don- de se plasma con mayor brillo el resultado de dicho proceso y su inserción en las corrientes estéticas nacionales, pues en ella conviven armónicamente producciones locales y aportaciones foráneas.

Al estudiar con detenimiento el programa ideológico que anima la obra se advierte, no sin cierta sorpresa, un carácter profundamente conservador que se vale de las nuevas tendencias estéticas propiciadas por la llustración para materializar mediante la perfecta integración de las artes un programa de clara vinculación jesuítica y por tanto contrarreformista. Resultan más singulares aún los principios que animaron este monumento si tenemos en cuenta que en Cádiz se viven por entonces años cruciales que preparan la inevitable caída del Antiguo Régimen. Este nuevo enfoque relega otras interpretaciones que tradicionalmente han relacionado las actividades de la Congregación del Retiro Espiritual con sociedades secretas e ideas revolucionarias. Por el contrario, el origen de la empresa se debe a una iniciativa muy personal protagonizada por el marqués de Valde-ínigo, mentor y mecenas de todo el conjunto. A su empeño debemos la existencia de la Santa Cueva que, sin lugar a dudas, es un magnífico compendio de la religiosidad de la Edad Moderna y punto culminante de la actividad artística desarrollada durante el Siglo de Oro gaditano.

Podemos confirmar que la mayor parte de la decoración escultórica en yeso del Oratorio responde a su tradicional atribución a Cosme Velázquez, concretamente coinciden con los rasgos estilísticos de su producción los altorrelieves de San Estanislao de Kostka y San Luis Gonzaga, así como gran parte del conjunto de ángeles. En cambio es evidente la intervención de otro artista, que relacionamos con José Fernández Guerrero, en la realización de otros grupos de ángeles. Ambos autores representan con gran dignidad el nivel artístico alcanzado por la escultura en Cádiz, aún cuando se trate de un período protagonizado por las creaciones arquitectónicas. Fue entonces cuando por primera vez la ciudad, tradicionalmente vinculada a los círculos artísticos sevillanos, se convierte en foco creador que irradia a su entorno, como hasta entonces lo había hecho Sevilla. La procedencia académica de sus protagonistas rompe con la habitual formación en talleres y frente a la tradición imaginera local se imponen nuevas técnicas, materiales y modelos internacionales en los que se funden el barroco de origen berninesco con un incipiente neoclasicismo de inspiración grecorromana.

Cosme Velázquez era el escultor más reconocido en los círculos locales, lo que explica que él se encargara del grueso de la obra cuando se plantea la construcción del oratorio eucarístico. Con su trabajo se produce un importante giro en la decoración escultórica de la Cueva, pues sólo una década antes se habían encargado las esculturas del oratorio bajo a maestros genoveses afincados en Cádiz y apegados a la tradición barroca. Su estilo denota, sin embargo, muchas vinculaciones con el barroco academicista de los primeros borbones, que se ven superadas totalmente en la producción de Fernández Guerrero, representante por ello de una nueva fase más cercana al Neoclásico. 
I. Sobre la burguesía gaditana pueden consultarse, entre otras obras, COMELLAS GARCÍA LLERA, José Luis, "Dinámica y mentalidad de la burguesía gaditana en el siglo XVIII", La burguesía mercantil gaditana (1650-1868), Cádiz, 1976 y DOMÍNGUEZ ORTIZ, Antonio, "La burguesía gaditana y el comercio con Indias desde mediados del siglo XVII hasta el traslado de la Casa de Contratación", La burguesía mercantil gaditana (1650-1868), Cádiz, 1976.

2. La mentalidad religiosa de los comerciantes gaditanos se analiza en MORGADO GARCÍA, Arturo, Iglesia y sociedad en el Cádiz del siglo XVIII, Cádiz, 1989 y "La religiosidad del comerciante gaditano dieciochesco. Posibles líneas de investigación", La burguesía de negocios en la Andalucía de la llustración, Cádiz, |99|, tomo II, pp. 374-375.

3. ANTÓN SOLÉ, Pablo, El Cádiz del conde O’Reilly (I 7801786), Cádiz, 1975. Para la biografía de Sebastián Martínez véase GARCÍA BAQUERO, Antonio, Libro y cultura burguesa en Cádiz: La biblioteca de Sebastián Martínez, Cádiz, 1988, pp. 25-35.

4. MOLINA Y ZALDÍVAR, Gaspar, marqués de Ureña, Reflexiones sobre la arquitectura, ornato y música del templo, Madrid, 1785. Sobre la vida y obra de este autor pueden consultarse SANZ, Virginia, "La teoría de la belleza y de la creación artística del marqués de Ureña", Revista de Ideas Estéticas $n^{\circ}$ 147, 1979, pp. 209-220 y "El marqués de Ureña y el neoclasicismo gaditano", Goya n I5I, Madrid, 1979, p. 19: PEMÁN MEDINA María, El viaje europeo del marqués de Ureña (1787-1788), Madrid, 1992, pp. 29-55

5. MORGADO GARCÍA, Arturo, "La difusión de las ideas jansenistas y regalistas en la España del siglo XVIII: La biblioteca de Fray Juan Servera, Obispo de Cádiz ( 1782)", III Encuentro de la llustración al Romanticismo, Cádiz, 1987, pp. 205-2I4.

6. OROZCO ACUAVIVA, Antonio, Orígenes de la Academia de Nobles Artes de Cádiz y artistas de su tiempo, Cádiz, 1973.

7. Sobre el origen de la Congregación del retiro Espiritual y biografía de Valde-Î́nigo ver GANDULFO E IROTO, José, Carta edificante o relación sumaria de la vida del exemplar sacerdote y obrero apostólico infatigable Sr. D. José Sáenz de Santa María, Marqués de Valde-Iñigo y fundador en Cádiz de la actual Santa Cueva, a la que trasladó la Congregación del Retiro Espiritual, Cádiz, 1807.

8. SEBASTIÁN, Santiago, "El programa iconográfico de la Santa Cueva de Cádiz" en Goya, nuevas visiones, Madrid, 1987.

9. ALONSO DE LA SIERRA FERNÁNDEZ, Lorenzo, "Iconografía y arquitectura de la Santa Cueva" en Goya y la Santa Cueva, Cádiz, 1997, pp. 27-28. sobre el influjo del jansenismo en el arte religioso de la España ilustrada véase, RODRÍGUEZ GUTIÉRREZ DE CEBALLOS, Alfonso, "La reforma de la arquitectura religiosa en el reinado de Carlos III. El neoclasicismo español y las ideas jansenistas", Fragmentos $n^{\circ}$ 12, 13 y 14, Madrid, 1998, pp. II5-127.

10. ATERIDO FERNÁNDEZ, Ángel, "Idea y contexto de una talla sevillana: La capilla del Cristo del Colegio Imperial de Madrid", Archivo Hispalense, $n^{\circ}$ 246, Sevilla, 1998, pp. 201-237.

1 I. Los datos sobre el proceso constructivo de las dos capillas que componen el Oratorio se recogen en GANDULFO E IROTO, José, Carta edificante... op. cit., pp. 50-65.

12. Sobre el origen del esquema compositivo de este templo filipense véase PEMÁN MEDINA, María, "La iglesia de San Felipe Neri, la arquitectura del templo y su significación a la luz de nuevos datos", Boletín del Museo de Cádiz II, Cádiz, 1980, pp. 89-100; JIMÉNEZ, Alfonso, "Antecedentes formales del Oratorio de San Felipe Neri de Cádiz", Boletín del Museo de Cádiz III, Cádiz, 1983-1984, pp. II3-122.

13. ALONSO DE LA SIERRA FERNÁNDEZ, Lorenzo, "Iconografía y arquitectura...", op. cit., pp. 23-25.

14. Sobre la obra de Goya en la Santa Cueva pueden consultarse, entre otras obras, TORRALBA, Federico, Goya en la Santa Cueva, Zaragoza, 1983; CLAVER CABRERO, Isabel,
"Goya en la Santa Cueva" en Goya y la Santa Cueva, Cádiz, 1997, pp. 29-36.

15. MORENO MORENO, Ana, "Las siete Palabras de Haydn" en Goya y la Santa Cueva, Cádiz 1997, pp.37-46.

16. Las nuevas tendencias artísticas de la llustración crearon una intensa polémica en torno a los materiales a utilizar en retablos y esculturas. Dos reales órdenes, la de Carlos III de I 777 y otra de su sucesor, Carlos IV dada en I79|, recogen esta inquietud prohibiendo la tradicional utilización de la madera a la que se da como alternativa el uso de mármol o estuco. En este ambiente surgieron varias iniciativas, como la propuesta del escultor zaragozano Francisco Albella para realizar retablos y esculturas en barro cocido. Importante fue el tratado de Pascual Diez para el uso del estuco, pero como bien le rebatió el estuquista Manuel Rata, su técnica no era la del estuco, que se hace con polvo de mármol y era muy poco frecuente en España, sino la del yeso. Véase MARTÍN GONZÁLEZ, Juan José, "Problemática del retablo bajo Carlos III", Fragmentos n I2, 13 y |4, Madrid, 1988, pp. 33-43.

Precisamente es el yeso la técnica elegida por Cosme Velázquez para sus creaciones de la Santa Cueva, obras consideradas tradicionalmente como estucos debido a la confusión comentada por Manuel Rata.

17. Los datos fundamentales de sus respectivas biografías los tomamos de RIBADENEIRA, Pedro, Flos Sanctorum, de la vida de los Santos, ed. Teresa Piferrer, Barcelona, I75I, pp. 235-250 y 476-48I. También pueden consultarse al respecto, entre otras, las obras de SACCHINI, NIEREMBERG, BÁRTOLI, CASARI, CEPARI Y LONGARO DEGL'ODDI.

18. RIBADENEIRA, Pedro, Flos Sanctorum... op. cit., p. 479.

19. La imagen de Santa Bárbara que aparece en el relieve ha sido también identificada con Santa Inés. ANTÓN SOLÉ, Pablo, La Santa Cueva..., op. cit., p. 21.

19. RIBADENEIRA, Pedro, Flos Sanctorum... op. cit., p. 238.

21. Ibídem, p. 238.

22. El programa iconográfico de este conjunto ha sido estudiado en SEBASTIÁN, Santiago, "El programa iconográfico..." op. cit.

23. BLANCO WHITE, José María, Autobiografía de Blanco White, Sevilla 1988, pp. 123-131.

24. MARTÍN MORENO, Antonio, Historia de la música andaluza, Sevilla, 1985, p. 278.

25. Este cambio se produjo en 1846 , para ubicar en su lugar el sepulcro de Valde-Íñigo.

26. Este modelo se utilizó con relativa frecuencia en la arquitectura española de la llustración. Uno de sus antecedentes inmediatos lo encontramos en el diseño de Ventura Rodríguez para la colegiata de Covadonga. Ver CHUECA GOITIA, Fernando, "Dibujos de Ventura Rodríguez para el santuario de Ntra. Sra. de Covadonga", Archivo Español de Arte ${ }^{\circ}$ 56, Madrid, 1943, pp. 61-87.

27. Sabemos que durante su estancia en Madrid, antes de establecerse definitivamente en Cádiz, Valde-Íñigo vivió bajo la dirección espiritual de "... un sabio y exemplar jesuita, de cuyo parecer no se apartaba..". También consta que fue especialmente brillante en la dirección de los ejercicios Espirituales de San Ignacio de Loyola. GANDULFO E IROTO, José, Carta edificante... op. cit., pp. 22 y 31.

28. MÂLE, Emile, El Barroco. El arte religioso del siglo XVII, Madrid, 1985, p. 372-373

29. CRUZ BAHAMONDE, Nicolás de la, Conde de Maule, Viaje de España, Francia e Italia, Cádiz, |8|2-18|3, tomo XIII, pp. 222-227.

30. Las consultas en diferentes archivos de la ciudad no han dado el fruto apetecido. El que en principio despertaba mejores expectativas, el propio de la Santa Cueva guardado actualmente en el Archivo Histórico Diocesano, no contiene 
ningún dato al respecto, pues casi todos sus fondos son posteriores a la inauguración del Oratorio.

31. Sobre su biografía véase PARDO CANALíS, Enrique, Escultores del siglo XIX, Madrid, 1951, pp. 10-16 y BANDA Y VARGAS, Antonio de la, "Evocación del escultor Cosme Velázquez en el $\mathrm{CL}$ aniversario de su muerte", Anales de la Academia de Bellas Artes de Cádiz n. 6, Cádiz, 1988, pp. 8788.

32. MELENDRERAS GIMENO, José Luis, "Cosme Velázquez, director de escultura en la Escuela de Bellas Artes de Cádiz", Gades n. II, Cádiz, 1983. p. 250.

33. Según Antonio de la BANDA Y VARGAS -"La escultura gaditana desde el academicismo al realismo", Enciclopedia Gráfica Gaditana, V. IV, n. I, Cádiz 1988, p. 37- este autor se había instalado ya en Cádiz en 1782 como colaborador de Torcuato Cayón.

34. Documento editado por MELENDRERAS GIMENO, José Luis, "Cosme Velázquez, ... ", op. cit., p. 253.

35. Datos concretos sobre las imágenes que ocupaban inicialmente el retablo mayor del Rosario se recogen en SANCHO DE SOPRANIS, Hipólito, "Algunas noticias para la biografía de Cosme Velázquez" en la Información del Lunes, Cádiz, 2 y 9 de diciembre de 1957. Sobre la extensa labor realizada por Cosme Velázquez en el templo del Rosario, anexo a la Santa Cueva, véase ALONSO DE LA SIERRA FERNÁNDEZ, Lorenzo, El retablo neoclásico en Cádiz, Cádiz, 1989, pp. 75-86.

36. MELENDRERAS GIMENO, José Luis, "Cosme Velázquez, ... ", op. cit, p. 250.

Destinados al mismo Templo realizó también cuatro cabezas de león para la sacristía mayor, una imagen de la Fe y los capiteles del retablo del sagrario. Asimismo se le atribuye el comulgatorio del sagrario Repetto Betes, José Luis. La obra del Templo de la Colegial de Jerez de la Frontera, Cádiz, 1978, p. 256.

37. LÓPEZ GARRIDO, José Luis y otros, Guía artística de San Fernando, San Fernando, 1989, p. 59

38. CRUZ BAHAMONDE, Nicolás de la, Conde de Maule, Viaje de España... op. cit., tomo XIII, p. 206.

39. ALONSO DE LA SIERRA FERNÁNDEZ, Juan y Lorenzo, Cádiz. Cuatro propuestas para conocer su patrimonio, (en prensa).

40. MELENDRERAS GIMENO, José Luis, "Cosme Velázquez, ... ", op. cit., pp. 250-25I.

41. ALONSO DE LA SIERRA FERNÁNDEZ, Lorenzo, El retablo neoclásico... op. cit., pp. 89-90.

42. BANDA Y VARGAS, Antonio de la, "Evocación del escultor Cosme Velázquez..., op. cit., pp. 87-88.

43. Se ha insistido, sin apoyo documental ni estilístico, en la vinculación de esta obra, ya desaparecida, con la labor de Cosme Velázquez, lo que ha llevado incluso a tomarla como modelo para el análisis de su producción como imaginero. BANDA Y VARGAS, Antonio de la, "La escultura gaditana...", op. cit., p. 38.

44. Existe constancia documental de la donación de este relieve por una devota a finales del siglo XVII, en cuyo testamento, entre otros legados a la Casa de Recogidas de la Conversión de San Pablo, incluye "... la lamina de Jaspe de relieve que esta sobre su puertta a la calle cuia historia es la misma Conversion que costo serca de dosientos pesos..." Archivo Histórico Provincial, Cádiz, protocolos notariales de Cádiz, legajo 5.583, folio 154. Esta circunstancia se recoge en ALONSO DE LA SIERRA FERNÁNDEZ, Juan y Lorenzo,
Guía artística de Cádiz, Cádiz, 1987, p. I06, pese a ello aún se insiste en su relación con Cosme Velázquez, véase al respecto BANDA Y VARGAS, Antonio de la, "La escultura gaditana... ", op. cit., p. 38.

45. BANDA Y VARGAS, Antonio de la, "La escultura gaditana...", op. cit., pp. 40-4I.

46. Ibídem, p. 42.

47. QUILES, Fernando y OLLERO, Francisco, "Noticias acerca de una escultura de Fernández Guerrero", Gades n 21, Cádiz, 1993, pp. 303-307.

48. ALONSO DE LA SIERRA FERNÁNDEZ, Lorenzo, "El retablo rococó en Cádiz y su entorno: Evolución y creadores", Archivo Hispalense $n^{\circ}$ 248, Sevilla, 1998, p. 101.

49. MÂLE, Emile, El Barroco... op. cit., pp. $92-93$

50. Sobre la difusión de este tema iconográfico en América véase SEBASTIÁN, Santiago, El Barroco Iberoamericano. Mensaje iconográfico, Madrid, 1990, p 342. Este autor señala una versión del tema realizada a inicios del siglo XVII por Luis Juárez. El mismo motivo, identificado como Los ángeles llevando la comunión a San Estanislao en casa del luterano, forma parte de una serie de lienzos pintados por José Padilla en 1759 para el convento de Tepozotlán en Méjico, hoy conservados en el Museo Nacional del Virreinato. TOUS SAINT, Manuel, Cuadros con escenas de la vida de San Estanislao de Kostka, Tepozotlán, 1978

Más cercano es el caso de Sevilla, en cuya iglesia de San Luis de los franceses encontramos una representación de la comunión milagrosa de San Estanislao en presencia de Santa Bárbara debida a Domingo Martínez y catalogada como San Estanislao enfermo recibiendo la comunión de manos de Santa Bárbara, ver SORO CAÑAS, Salud, Domingo Martínez, Sevilla, 1982, pp. 88-89.

51. CRUZ BAHAMONDE, Nicolás de la, Conde de Maule, Viaje de España... op. cit, tomo XIII, p. 227.

52. Los documentos de la Santa Cueva conservados en el Archivo Histórico Diocesano de Cádiz guardan numerosos recibos de obras de mantenimiento, entre ellas de pintura, a las que seguramente obedecen los múltiples repintes e intervenciones documentados en los altorrelieves durante el proceso de restauración.

53. En 1806 el obispo diocesano dio licencia para colocar un retrato de Valde-Iñigo en la sacristía de la parroquia del Rosario, obra realizada por Franz Xavier Riedmayer a iniciativa del padre Gandulfo, quien pudo ser también el promotor del retrato del mismo pintor que se colocó sobre el presbiterio de la Santa Cueva. CRUZ BAHAMONDE, Nicolás de la, Conde de Maule, Viaje de España... op. cit, tomo XIII, p. 226.

54. Ibídem, p. 225.

55. Un testimonio contemporáneo, la Guía Rosetty, hace referencia a ello, aunque no llegó a publicar su anunciada descripción detallada: "Por falta de espacio y bien a nuestro pesar aplazamos para otra edición el ocuparnos con el detenimiento que se merecen de las importantísimas obras de restauración y ornato que en el año próximo pasado y principio del que toca a su término se han realizado en la Cueva y en el Oratorio, obras costosas y notables, en las que llaman sobremanera la atención los notables trabajos efectuados bajo la inteligentísima dirección del acreditado artista establecido en la capital de Andalucía D. Antonio Cavallini, ya conocido ventajosamente en esta ciudad por los que en unión de un hermano suyo realizó en I87| en la hermosa sala capitular del Ayuntamiento...". ROSETTY, José, Guía de Cádiz, El Puerto de Santa María, San Fernando y el Departamento, Cádiz, I888, p. 205. 